\section{DAMAGE PROPAGATION AND THERMOGRAPHY IN DISCONTINUOUS CARBON FIBER COMPOSITE (DCFC) UNDER TENSILE (FATIGUE) LOADING}

\author{
Jefri Balea*, Emmanuel Valotb, Olivier Politb
}

aDepartment of Mechanical Engineering, Universitas Nusa Cendana, Kupang 85001, Nusa Tenggara Timur, Indonesia bLaboratoire Energétique Mécanique Electromagnétisme (LEME), Université Paris Nanterre, Ville d'Avray, 92410, France

\section{Article history \\ Received \\ 30 April 2019 \\ Received in revised form \\ 29 September 2019 \\ Accepted \\ 2 October 2019 \\ Published online \\ 25 December 2019 \\ *Corresponding author jefri_bale@staf.undana.ac.id}

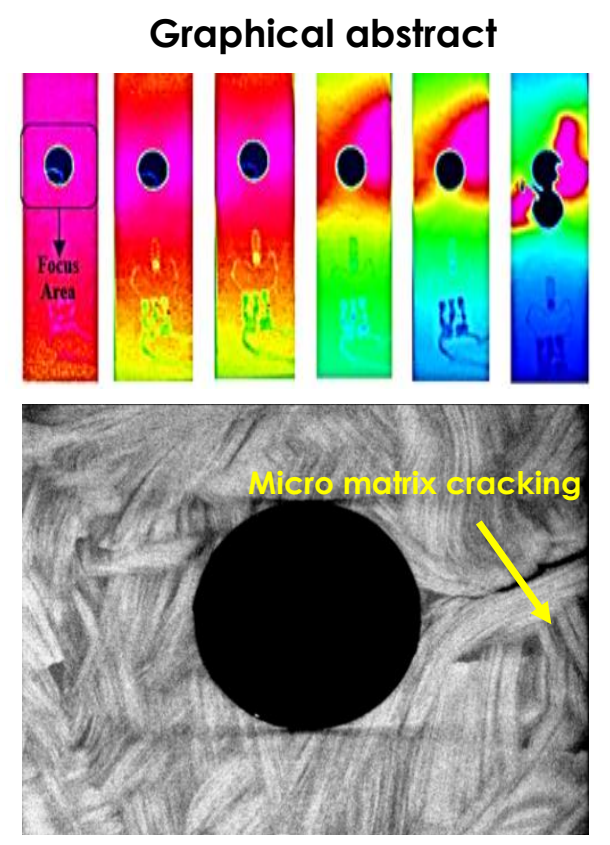

\begin{abstract}
The discontinuous carbon fiber composite (DCFC) has a different damage behaviour due to non homogenuous sub structure. Consequently, monitoring and diagnosis of DCFC damage mechanisms require the application of a contactless method in real-time operation, i.e., non destructive method of thermography. The aim of this study is to investigate the damage propagation of DCFC material under tensile (fatigue) condition with non destructive testing (NDT) thermography method. Under fatigue testing, temperature evolutions were monitored by an Infra-Red (IR) camera. The results show that damage propagation and thermal response indicated the similar behaviour which consists of three stages. At the beginning, low temperature increased until $\approx 10 \%$ of fatigue life due to the initial damage. The initial damage propagated and the temperature reached the stable thermal state due to the saturation in the damage appearance of micro cracking of matrix and chip until $\approx 80 \%$ of fatigue life. At the last $\approx 20 \%$ of fatigue life, damage continued to propagate and provoked the occurrence of macro damage that induced the final failure indicated by highest peak of temperature. The analysis from the experiment results concluded that thermal response relates with the damage propagation of DCFC under fatigue loading.
\end{abstract}

Keywords: Thermography, DCFC, damage, tensile, fatigue loading

(C) 2020 Penerbit UTM Press. All rights reserved

\subsection{INTRODUCTION}

Discontinuous carbon fiber composite (DCFC) is prepeg-based discontinuous of randomly distribution of carbon chip-reinforced polymer composite, as known as Quantum Lytex 4149 and HexMC under various manufaturer and brands [1-2]. The main advantage of this type of material is its good suitability to be molded in complex geometries with lower manufacturing costs and at higher rates that justify their adoption to reduce overall part acquisition costs [3-4]. Several studies about mechanical and damage behaviour of DCFC were performed by previous authors [5-10]. They concluded that the failure of DCFC is the combination of two failure modes: cracking caused separation along the surface that perpendicular to the chip axis and delamination caused separation along the thickness that parallel to the chip length under static loading.

Under fatigue, DCFC as a polymer composite material has a complex and different phenomenon since several factors contribute to the damage of material, such as: non homogenuous sub structure, insensitive to circular notches, highly modulus variation 
[11-14]. Consequently, monitoring and diagnosis of these different forms of damage mechanisms require the application of a contactless method in real-time operation, i.e non destructive method. A thermography technique has been used to study the evolution of temperature on the specimen surface of composite material under fatigue loading and can characterise the fatigue and damage behaviour due to the degradation by fatigue loading [15-20].

Recently, Bale et al. [21], studied about thermal analysis and damage evolutions of DCFC to determine the high cycle fatigue strength (HCFS) under fatigue loading. The results indicated that thermography and energy dissipation approaches can be used to determine HCFS of DCFC material, which is much more time consuming. This study presented the propagation of damage behaviour and thermography method of DCFC under tensiontension fatigue loading experiments.

\subsection{METHODOLOGY}

The open hole tension (OHT) specimen test is $60 \%$ of random discontinuous (chip form) carbon fiber volume as the reinforcement and epoxy matrix. Chip dimensions are $50 \mathrm{~mm}$ length and $8 \mathrm{~mm}$ width where fabricated into composite material under compression molding. The test was carried out on INSTRON Machine $8501100 \mathrm{kN}$, equipped with mechanic grips of $20 \mathrm{kN}$ max capacity. Local strain was measured using single strain gage with a gage length of $5 \mathrm{~mm}$. Temperature evolutions during the cyclic tests were monitored by an Infra-Red (IR) camera. Figure 1 below shows the schematic diagram of experimental set up.

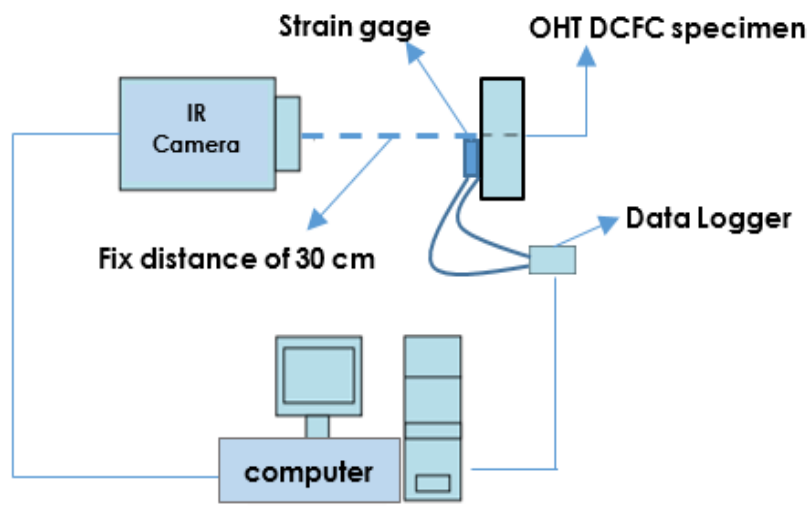

Figure 1 Schematic diagram of experimental set up

The fatigue tests were performed under load control, at a stress ratio, $R$, equal to 0.1 , i.e., tension tension loading and constant $3 \mathrm{~Hz}$ of frequency. An IR camera was placed in front of the specimen with fix distance, i.e., $30 \mathrm{~cm}$. The test specimen is rectangular shape with an open hole condition, as seen in Figure 2.

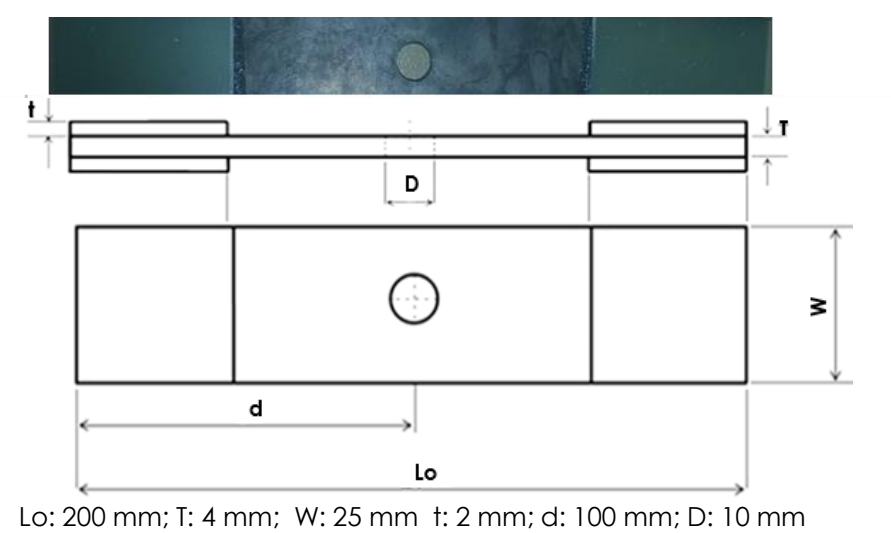

Figure 2 DCFC specimen

\subsection{RESULTS AND DISCUSSION}

\subsection{Stiffness Degradation and Damage Propagation}

The fatigue tests conducted with different of load level, i.e., $60 \%$ of ultimate tensile strength (UTS) and 75 $\%$ UTS. Figure 3 shows the stiffness degradation (E/EO) as a function of fatigue life (Nf). The stitffness degradation were in the range between 1 and 0 .

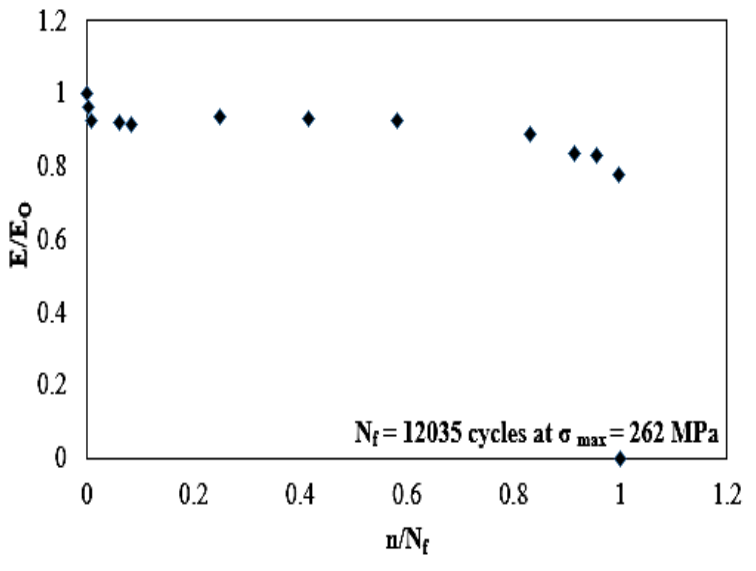

a. $60 \%$ UTS

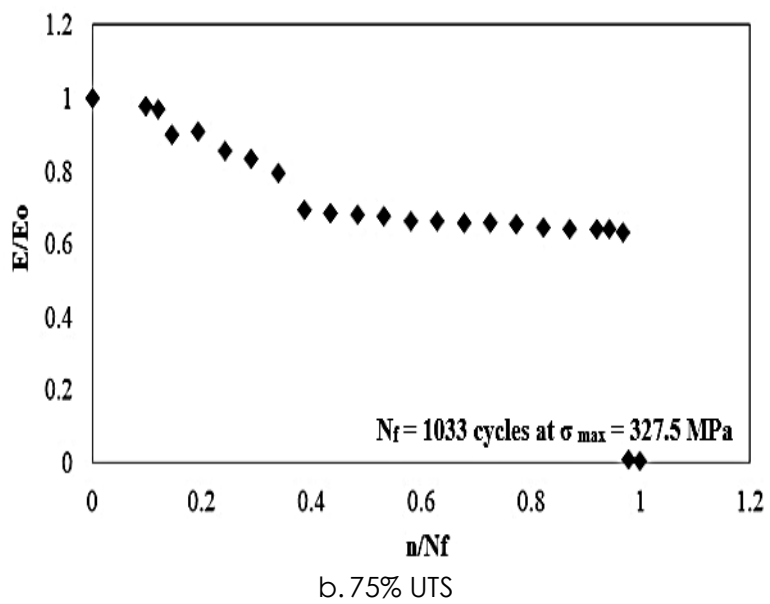

Figure 3 Stiffness degradation of DCFC 
From Figure 3, under different load level, specimens failed at different number of fatigue life (Nf) where $60 \%$ of UTS generates Nf of 12035 cycles and load level of $75 \%$ of UTS has a shorter fatigue life of 1033 cycles. it is noted that DCFC specimens experience the change in modulus or stiffness as a function of fatigue cycles. The Stiffness degradation curve or the decrease trend in material modulus has been commonly used to express the state of cumulative damage $D$ in polymer composite material as a function of loading cycles [14], where defined as:

$$
D=1-\frac{E}{E_{0}}
$$

where $\mathrm{E}$ and $\mathrm{E}_{0}$ are the residual and initial modulus, respectively. Figure 4 shows the cumulative damage and stiffness degradation. According to Equation (1), the accumulate damage will be in the range between 0 and 1 .

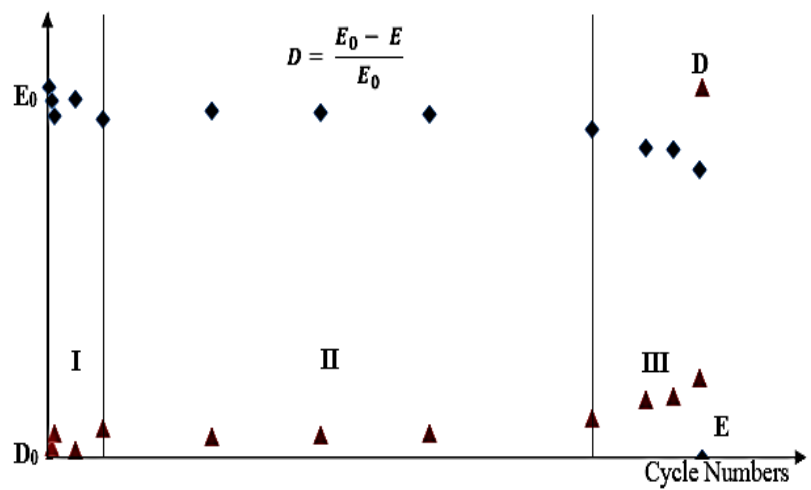

a. $60 \%$ UTS

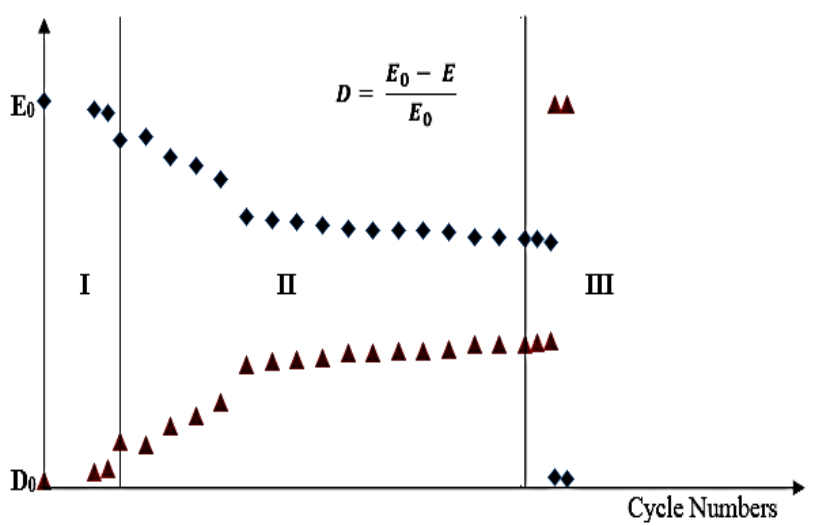

b. $75 \%$ UTS

Figure 4 Cummulative damage versus stiffness degradation of DCFC

In general, under fatigue loading, the first small drop of stiffness is associated with the presence of initial micro matrix cracking damage mechanism in micro scale. Then, the stiffness propagates into gradual decrease as also the damage seems to increase and develop into others mechanisms, such as interfacial matrix/fiber debonding and delamination. The final stage of damage propagation leads to a decline of stiffness with an increasing amount of damage mechanisms, such as fiber breakage and delamination growth [22-24]. The ilustration of stiffness degradation and damage propagation of fiber composite can be seen in Figure 5.

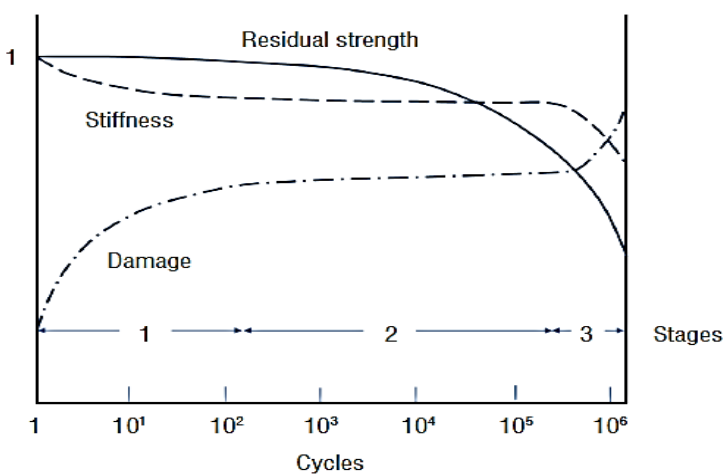

Figure 5 The three characteristic stages of fatigue damage in composites [25]

For DCFC specimen, under fatigue loading, it shows similar behaviour compared to fiber composite. In both $D$ versus $E$ /Eo curves show the same behaviour which consists of three stages:

- The initial area (stage I) shows an initial rapid decrease trend of stiffness along with an increase of damage propagation rapidly. This stage takes $10 \%$ of stiffness reduction and presence of initial micro damage growth of matrix cracking during the first period of fatigue life.

- An intermediate area (stage II) shows a gradual decrease trend and forms into an approximately linear fashion with respect to $70-80 \%$ of second fatigue life period. In this stage, a stiffness reduction of $5-15 \%$ occurs due to the stable propagation of chip/matrix debonding and chip cracking.

- The Final area (stage III) forms a rapid stiffness reduction of $5-10 \%$ during the $10-20 \%$ with the respect to the cycles numbers. In the final stage, chip breakage take places and which caused separation along the thickness and for the last 2-5 $\%$ of fatigue life, a final catastrophic failure occurs as a consequence of sudden increase of damage propagation. The boundary between region II and III is the so called fatigue limit [26].

Figure 6 shows the microcrack of matrix during the first period of the fatigue life as an initial cause of specimen's failure. 


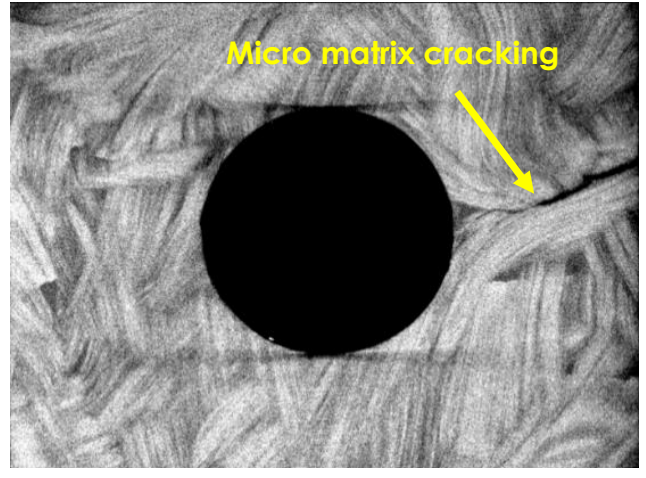

Figure 6 CT scan image of micro matrix cracking

\subsection{Thermal Analysis based on Thermography Observation}

The basic idea of thermography is to apply infrared frequency range of electromagnetic radiation emitted by object under research to obtain information concerning its selected physical properties or processes taking place within this object. The camera thermograpy will absorbs the IR energy emitted by the object and it transforms the amount of infrared energy into the temperature then represented in the form of thermographic images. The ilustration of principle of measurement by themography as shown schematically in Figure 7.

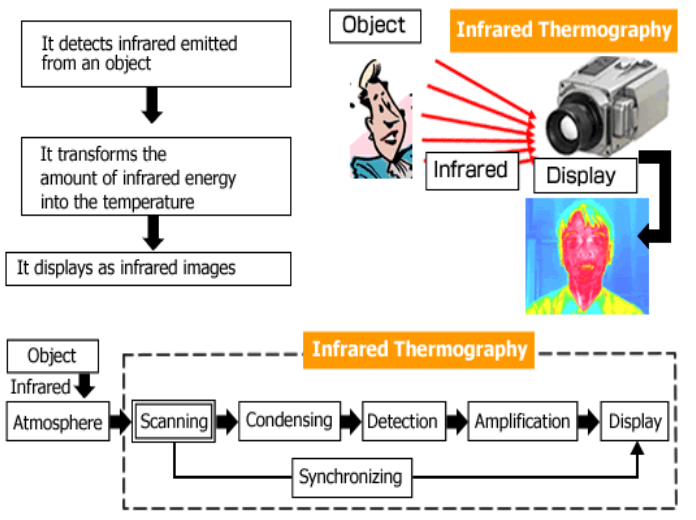

Figure 7 The principle of thermography [27]

It is well known that, thermography can fulfill the need of a non contact technique and real time inspection of damage detection under dynamic loading conditions [28-34] due to the transformation of damage in an irreversible way into heat [35]. An ilustration of thermal evolution during a fatigue test can be seen in Figure 8.

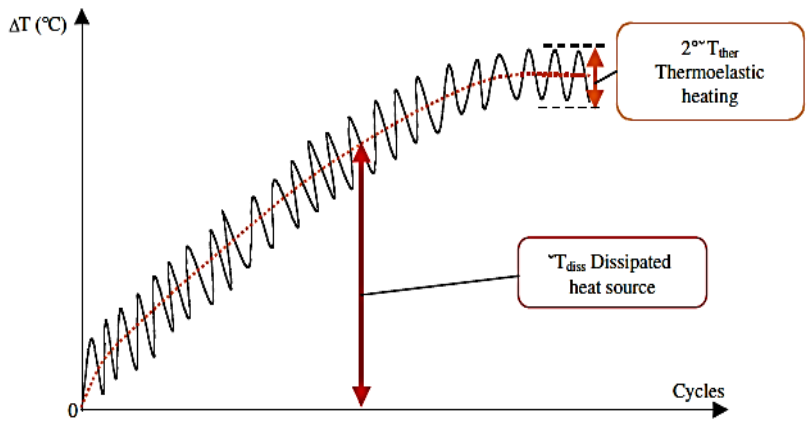

Figure 8 Thermal evolution during a fatigue test [15]

The aim of this study is to have a relationship between temperature evolution and damage propagation. Figure 9 shows the temperature change for certain cycles until failure, respectively. The focus area is localised around the hole.

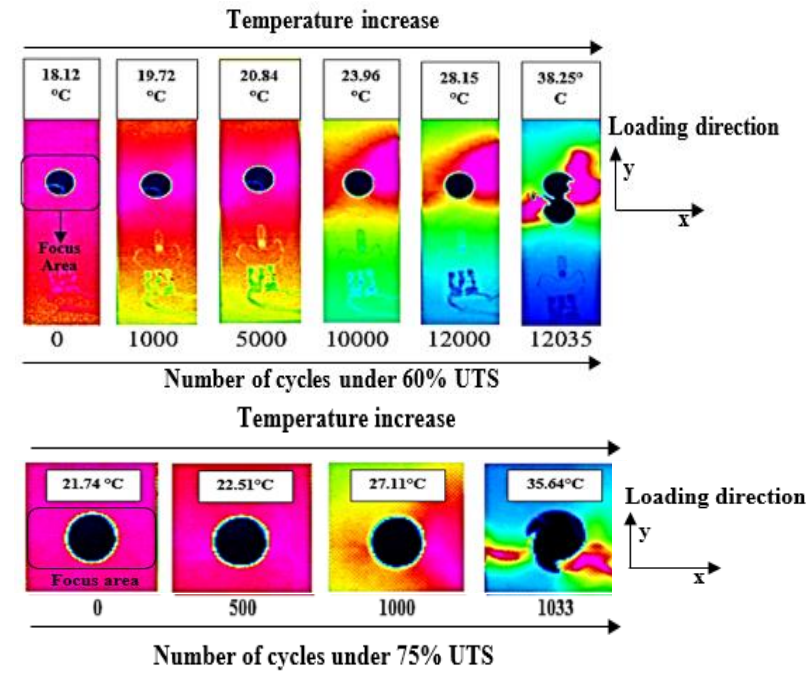

Figure 9 Temperature images of DCFC under fatigue loading

The focus area, which the damage area at the edge of the hole, is shown in Figure 9 for the $60 \%$ UTS and $75 \%$ UTS specimen. The temperature shows a similar slow increase until it reaches at $\mathrm{N}_{f}$ around 10000 cycles for $60 \%$ UTS and 1000 cycles for $75 \%$ UTS. A significant increase of temperature occurs at the end of fatigue life for both specimens and reaches $\Delta \mathrm{T} \approx$ $20^{\circ} \mathrm{C}$ for $60 \%$ UTS and $\Delta \mathrm{T} \approx 14^{\circ} \mathrm{C}$ for $75 \%$ UTS. All temperature formation during the fatigue test can be seen in Figure 10 


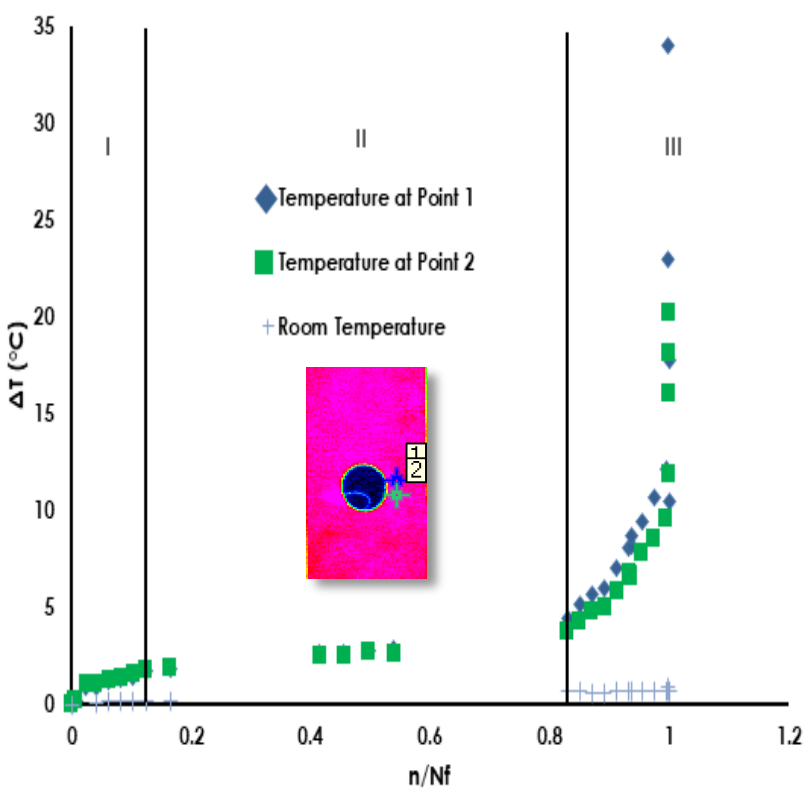

a. $60 \%$ UTS

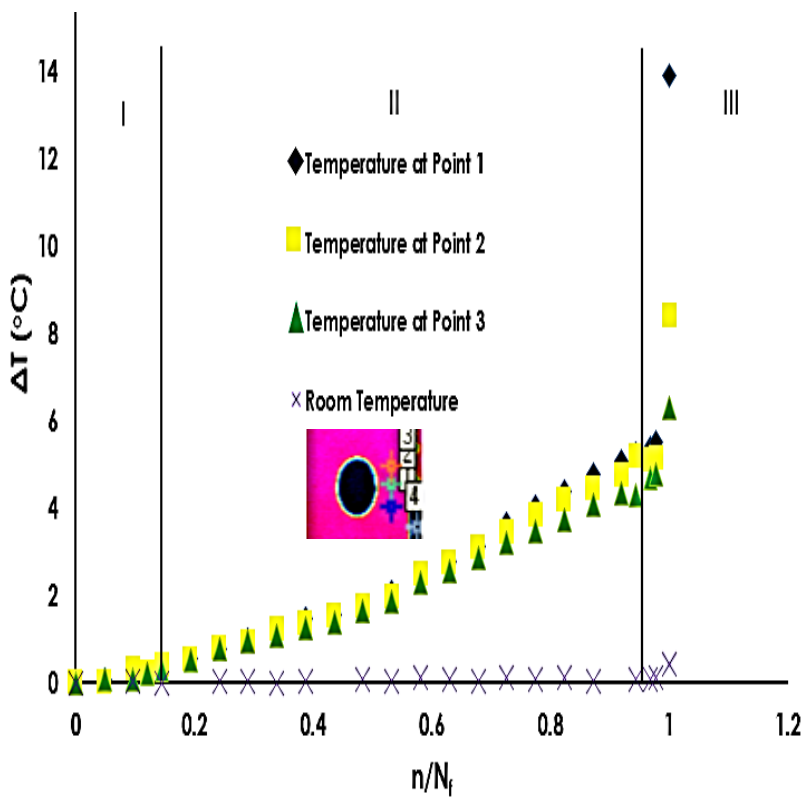

b. $75 \%$ UTS

Figure 10 Thermal evolution of DCFC under fatigue loading

When damage occurs, it represents the energy which gradually released. The energy that has been absorbed is sufficient to create micro-crack, enlarging the pre-existent ones, and create new inner and interfacial debonding and chip cracks then leads to final failure. The heat generated from the energy release then detected by the IR camera that showed an increase in temperature in the area of damage. It shows temperature increase behaviour at $\Delta \mathrm{T} \approx 1-3^{\circ} \mathrm{C}$ until $\approx 10 \%$ of fatigue life due to the initial damage. The initial damage propagates and the temperature reaches the stable thermal state (an example of a slope of $0.0004^{\circ} \mathrm{C} / \mathrm{cycle}$ from 1200 to around 10000 cycles for $60 \%$ UTS) due to the saturation in the damage [15]. Each peak of temperature indicates different type of damage mechanisms. We found that temperature reaches at $\Delta \mathrm{T} \approx 1-5{ }^{\circ} \mathrm{C}$ is directly associate with the appearance of micro cracking of matrix and chip. After that, damage continues to propagate and temperature starts to show a higher increase until reaches at $\Delta T \approx 12^{\circ} \mathrm{C}$. The $\Delta T \approx 6-8^{\circ} \mathrm{C}$ for $60 \%$ UTS and $\Delta T \approx 4-5^{\circ} \mathrm{C}$ for $75 \%$ UTS is related with the appearance of interfacial damage. The higher temperature of interfacial damage is in fact due to absorb more energy of damage. From the temperature evolution during test, the presence of macro damage indicate the area of final failure which is exist and concentrate in the region of focus area around the hole. In sum, initial macro damage provokes the occurrence of catastrophic or final failure of the specimen that induce the highest peak of temperature at $\Delta T \approx 20-34^{\circ} \mathrm{C}$ for $60 \%$ UTS and $\Delta T \approx$ $13-14{ }^{\circ} \mathrm{C}$ for $75 \%$ UTS suddenly. Based on the temperature evolution of DCFC above under fatigue test, an approximate of temperature behaviour of DCFC until fatigue limit can be approached in a form of an empirical relationship, which is expressed as:

$$
\Delta \mathrm{T}=\mathrm{m} . \mathrm{Nf}
$$

where:

$\Delta \mathrm{T}=$ temperature evolution $\left({ }^{\circ} \mathrm{C}\right)$

$\mathrm{m}=$ temperature slope $\left({ }^{\circ} \mathrm{C} / \mathrm{cycle}\right)$

$\mathrm{Nf}=$ Number of fatigue life (cycle)

Table 1 shows the equation of $\triangle T$ of DCFC during the fatigue loading for each load level.

Table 1 The equation of $\triangle T$ evolution of DCFC

\begin{tabular}{cc}
\hline Stage & $60 \%$ of UTS \\
\hline I & $\Delta T=0.0033\left({ }^{\circ} \mathrm{C} /\right.$ cylce $) \times N f($ cycles $)$ \\
Stage & $\Delta T=0.0004\left({ }^{\circ} \mathrm{C} /\right.$ cylces $) \times N f($ cycles $)$ \\
\hline$I$ & $\Delta T=0.008\left({ }^{\circ} \mathrm{C} /\right.$ cylces $) \times N f($ cycles $)$ \\
II & $\Delta T=0.005\left({ }^{\circ} \mathrm{C} /\right.$ cylces $) \times N f($ cycles $)$
\end{tabular}

The comparison between the thermal evolution and the damage propagation can be seen in Figure 11. 


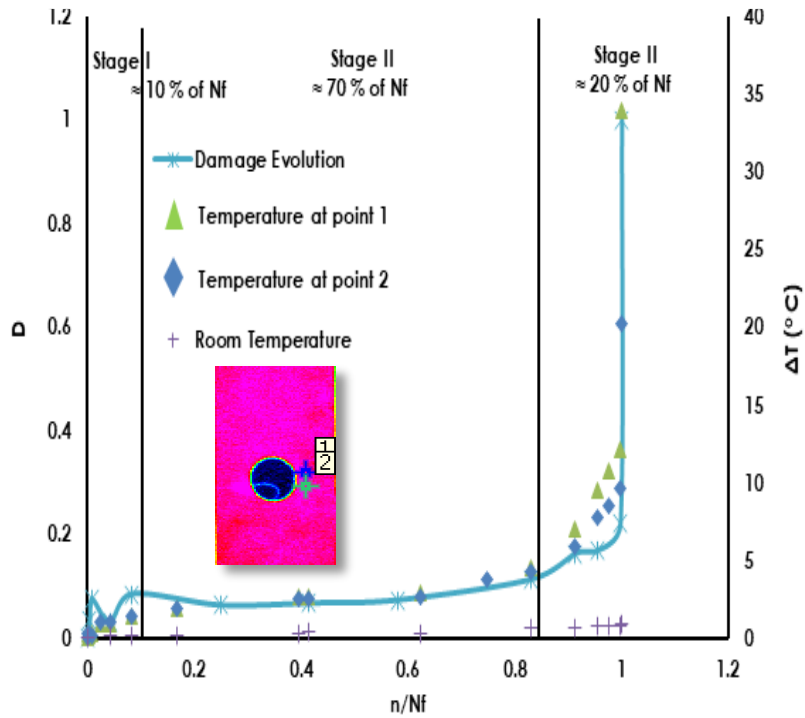

a. $60 \%$ UTS

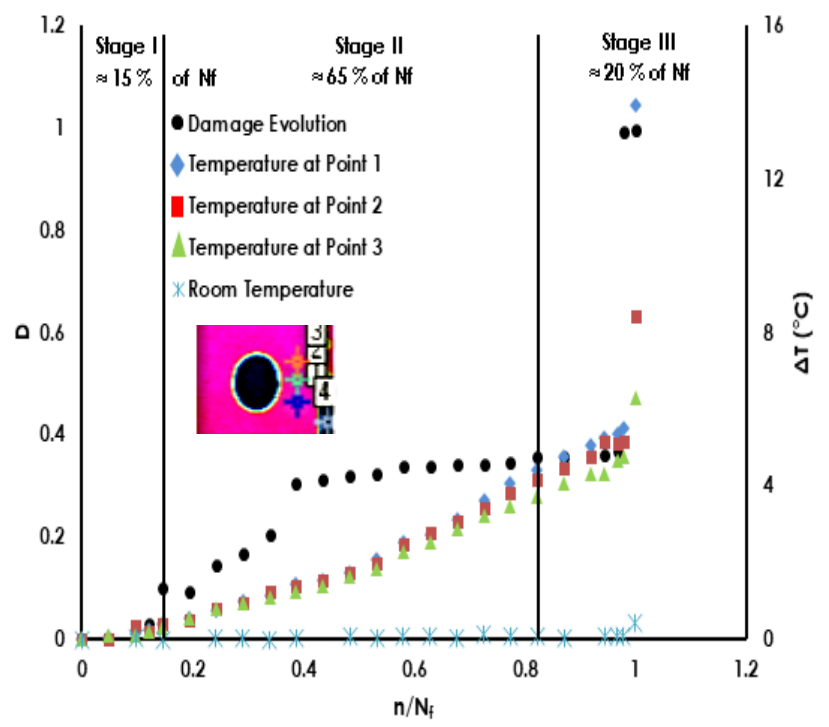

b. $75 \%$ UTS

Figure 11 Comparison between the temperature evolution and the damage propagation of DCFC under fatigue loading

From Figure 11, temperature evolution and damage propagation show the same 3 (three) increase phases characterised by low phase, slowgradual phase, and high-sudden phase. Therefore, it can be noted that the temperature behaviour $(\Delta T$ response) of DCFC under fatigue loading can be used as one of damage parameter and not only stiffness degradation which has been used in conventional method. This confirms the results from previous studies [15, 18-19, 21], which conclude that thermal dissipation relates to the damage evolution and can effectively estimates the damage behaviour of carbon fiber composite material.

\subsection{CONCLUSION}

This study presents experimental results of damage propagation and temperature evolution on discontinuous carbon fiber composite (DCFC) under tensile (fatigue) loading. The results confirm that thermal response of $\Delta T$ on specimen surface can be effectively used to identify the damage propagation of DCFC. Damage propagation and temperature evolution of DCFC form an increasing phase consisting of low phase due to initial micro damage growth of matrix cracking, slow-gradual phase caused by the stable propagation of chip/matrix debonding and chip cracking, and high-sudden phase as a consequence of final failure dominated by chip breakage. Therefore, thermal response is highly potential parameter to be explored in relation to composite material damage from various dynamic test conditions in the future.

\section{Acknowledgement}

The authors thank to PSA Peugeot Citroën France for providing facilities.

\section{References}

[1] Porter, J. 2004. Moving Closer to the Goal of Cost Effective Complex Geometry Carbon Composite Parts. 19th ASC Technical Conference, Atlanta.

[2] Boeing 787 Features Composite Window Frames. 2007. Reinforced Plastics. 51 (3): 4.

[3] Boursier, B., and Lopez, A. 2019. Failure Initiation and Effect of Defects in Structural Discontinuous Fiber Composites. Hexcel Research and Technology. Retrieved from http://www.hexcel.com; 11 February, 2019.

[4] Harper, L. T., Burn, D. T., Johnson, M. S., and Warrior, N. A. 2017. Long Discontinuous Carbon Fibre/Polypropylene Composites for High Volume Structural Applications. Journal of Composite Materials. 0: 1-16.

[5] Feraboli, P., Peitso, E., Deleo, F., Cleveland, T., Graves, M., and Stickler, P. 2019. Characterization of Discontinuous Carbon Fiber/Epoxy Systems for Aerospace Applications. Retrieved from http://www.aa.washington.edu; 27 January, 2019.

[6] Feraboli, P., Peitso, E., Cleveland, T., Stickler, P., and Halpin C. J. 2009. Notched Behaviour of Prepeg-Based Discontinuous Carbon Fiber/Epoxy Systems. Composites: Part A. 40: 289-299.

[7] Feraboli, P., Cleveland, T., Stickler, P., and Halpin, C. J. 2010. Stochastic Laminate Analogy for Simulating the Variability in Modulus of Discontinuous Composite Materials. Composites: Part A. 41: 557-570.

[8] Feraboli, P., Cleveland, T., Ciccu, M., Stickler, P., and DeOto, L. 2010. Defect and Damage Analysis of Advanced Discontinuous Carbon/Epoxy Composite Materials. Composites: Part A. 41: 888-901.

[9] Feraboli, P., Peitso, E., Deleo, F., and Cleveland, T. 2009. Characterization of Prepeg-based Discontinuous Carbon Fiber/Epoxy Systems. Journal of Reinforced Plastics and Composites. 28: 1191-1214.

[10] Bale, J. 2015. The Discontinuous Carbon Fiber Composite: A Review of the Damage Characteristics. Lontar Jurnal Teknik Mesin Undana. 2: 09-14. 
[11] Feraboli, P., Peitso, E., and Cleveland, T. 2009. Modulus Measurement for Prepeg-Based Discontinuous Carbon Fiber/Epoxy Systems. Journal of Composite Materials. 43(19): 1947-1965.

[12] Turtle, M., Shifman, T., and Boursier, B. Simplifying Certification of Discontinuous Composite Material Forms Primary Aircraft Structures. Hexcel Research and Technology. Retrieved from: http://www.hexcel.com; 27 January, 2019.

[13] Bond, M. D., Harper, L. T, Turner, T. A., and Warrior, N. A. Full - Field Strain Measurement of Notched Discontinuous Carbon Fiber Composites. Retrieved from: http://www.iccm-central.org; 27 January, 2019.

[14] Qian, C., Harper, L. T., Turner, T. A., and Warrior, N. A. 2011. Notched Behaviour of Discontinuous Carbon Fiber Composites: Comparison with Quasi-isotropic Non-crimp Fabric. Composites: Part A. 42: 293-302.

[15] Toubal, L., Karama, M., and Lorrain, B. 2006. Damage Evoution and Infrared Thermography in Woven Composite Laminates under Fatigue Loading. International Journal of Fatigue. 28: 1867-1872.

[16] Bayat. M., Safizadeh M. S., and Moradi, M. 2019. Numerical and Experimental Study for Assessing Stress in Carbon Epoxy Composites using Thermography. Infrared Physics and Technology. 98: 108-113.

[17] Li, Y., Zhang, W., Yang, Z., Zhang, J., and Tao, S. 2016. LowVelocity Impact Damage Characterization of Carbon Fiber Reinforced Polymer (CFRP) using Infrared Thermography. Infrared Physics \& Technology. 76: 91-102.

[18] Li, Y., Yang, Z., Zhu, J., Ming, A., Zhang, W., and Zhang, J. 2016. Investigation on the Damage Evolution in the Impacted Composite Material based on Active Infrared Thermography. NDT \& E International. 83: 114-122.

[19] Montesano, J., Fawaz, Z., and Bougherara, H. 2013. Use of Infrared Thermography to Investigate The Fatigue Behaviour of A Carbon Fiber Reinforced Polymer Composite. Composite Structure. 97: 76-83.

[20] Risitano, A., and Risitano, G. 2013. Cumulative Damage Evaluation in Multiple Cycle Fatigue Tests Taking into Account Energy Parameters. International Journal of Fatigue. 48: 214-222.

[21] Bale, J., Valot, E., Monin, M., Polit, O., Bathias, C., and Soemardi, T. 2016. Experimental Analysis of Thermal and Damage Evolutions of DCFC under Static and Fatigue Loading. Revue des Composites et des Matériaux Avancés. 2: 165-184.

[22] Bale, J., Valot, E., Polit, O., Bathias, C., Monin, M., and Soemardi, T. 2017. Thermal Phenomenon of Glass Fibre
Composite under Tensile Static and Fatigue Loading. Journal of Mechanical Engineering and Sciences. 11:27552769

[23] Kaminski, M., Laurin, F., Maire, J. F., Rakotoarisoa. C., and Hémon, E. 2015. Fatigue Damage Modeling of Composite Structures: The Onera View Point. AerospaceLab. 1-12.

[24] Schulte, K. 1993. Damage Monitoring in Polymer Matrix Structures. Journal de Physique. 4(3): 1629-1636.

[25] Reifsnider, K. L. 1991. Fatigue of Composite Materials. K. L. Reifsnider (Ed). Elsevier Science Publishing Co. New York.

[26] Talreja, R. 2008. Damage and Fatigue in Composites - A Personal Account. Composites Science and Technology. 68: 2585-2591.

[27] Infrared. What is Infrared Thermography. Retrieved from http://www.infrared.avio.co.jp/en/products/irthermo/wha t-thermo.html; 27 January, 2019.

[28] De Finis, R., Palumbo, D., and Galietti, U. 2019. Fatigue Damage Analysis of Composite Materials using Thermography-Based Techniques. Procedia Structural Integrity. 18: 781-791.

[29] Muc, A., Barski, M., Chwal, M., Romanowicz, P and Stawiarski, A. 2018. Fatigue Damage Growth Monitoring for Composite Structures with Holes. Composite Structures. 189: 117-126.

[30] Stawiarski, A. 2018. The Nondestructive Evaluation of the GFRP Composite Plate with an Elliptical Hole under Fatigue Loading Conditions. Mechanical Systems and Signal Processing. 112: 31-43.

[31] Prakash, R. V., and Maharana, M. 2017. Damage Detection using Infrared Thermography in a Carbon-Flax Fiber Hybrid Composite. Procedia Structural Integrity. 7: 283-290.

[32] Emery, T. R., and Dulieu-Barton, J. M. 2010. Thermoelastic Stress Analysis of Damage Mechanisms in Composite Materials. Compos Part A: Appl Sci Manuf. 41 (12): 17291742.

[33] Addepalli, A., Zhao, Y., Roy, R., Galhenege, W., Colle, M. Yu, J., and Ucur, A. 2019. Non-Destructive Evaluation of Localised Heat Damage Occurring in Carbon Composites using Thermography and Thermal Diffusivity Measurement Measurement. 131: 706-713.

[34] Colombo, C., Libonati, F., and Vergani, L. 2012. Fatigue Damage in GFRP. International Journal of Structure Integrity. 3(4): 424-440.

[35] Chrysochoos, A. 2002. Infrared Thermography, a Potential Tool for Analysing the Material Behaviour. Me'ca Indus. 3: 3-14. 